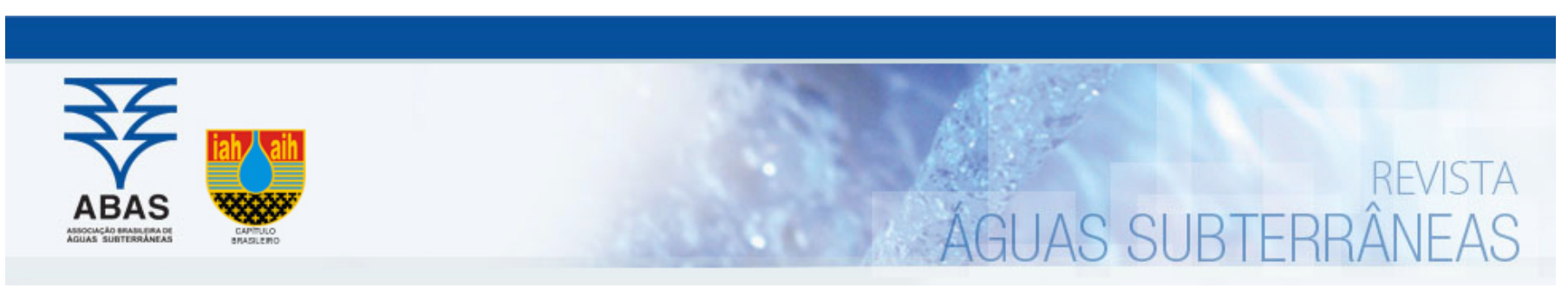

\title{
Avaliação da qualidade microbiológica da água do córrego Barreirinho no município de Ibirité-MG. Uma comparação com o Kit Enzquik
}

\author{
Microbiological Quality Evaluation of Barreirinho Stream Water in Ibirité City - \\ MG. - A Comparison to Enzquik Kit
}

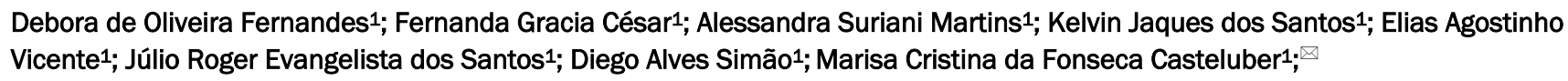

1 Universidade do Estado de Minas Gerais (UEMG), Ibirité, MG

$\bowtie$ deborafernandes95@hotmail.com, fernandagraciacesar@hotmail.com, alessandrasuriani bio@hotmail.com, kelvinpinheiro32@hotmail.com, elias bio@hotmail.com, julio.roger13@gmail.com, diego.alvesth@gmail.com, marisagap@yahoo.com.br

Resumo

Palavras-chave:

Água.

Análise microbiológica.

Ibirité.

Detecção Rápida EnZquik.

O córrego Barreirinho, objeto desse estudo, situado no município Ibirité-MG, vem sendo utilizado pela população do entorno principalmente para irrigação de hortaliças, mas a qualidade microbiológica do mesmo ainda não foi avaliada. 0 objetivo deste estudo foi avaliar os parâmetros físico-químicos e microbiológicos da água deste córrego e compará-los com os padrões da Resolução N³57 do CONAMA. A metodologia utilizada foi a técnica de tubos múltiplos e análise com o Kit de Detecção Rápida EnZquik. Os resultados das análises deste estudo demonstraram que os pontos próximos à nascente e no meio do curso d'água, com irrigação das hortas, mostram resultados semelhantes; as águas nesses pontos podem ser utilizadas para irrigação de hortaliças e consumo humano após tratamento simplificado. Os testes apontaram que no final do curso, na área urbana, a água é imprópria para qualquer uso. A semelhança entre os resultados obtidos com as duas técnicas permite sugerir que o Kit Enzquik, pode futuramente substituir técnicas utilizadas em laboratório, diminuindo o tempo de incubação e análise com outras metodologias, gerando um resultado quase instantâneo.

Keywords

Water.

Microbiological analysis.

Ibirité.

Quick Detection EnZquik..

Revisado por pares.

Recebido em: 26/03/2018.

Aprovado em: 26/06/2018.

\begin{abstract}
The Barreirinho stream, which is the object of this study, located in the city of Ibirité-MG, has been used by the surrounding population mainly for irrigation of vegetables, but the microbiological quality of the same has never been evaluated. The objective of this study was to evaluate the physical-chemical and microbiological parameters of the water of this stream and compare them with the standards of Resolution No. 357 of CONAMA (National Council of the Environment). The methodology used was the multiple tube technique and analysis with the EnZquik Quick Detection Kit. The results of the analyzes of this study showed that the points near the source (PN) and irrigation of the vegetable gardens $(\mathrm{IH})$, are in agreement with the standards established by Resolution No. 357 of CONAMA, these points can be used for irrigation of vegetables and human consumption after simplified treatment. The tests pointed out that the DU (Urban Waste) point is unsuitable for any purpose. The similarity between the results obtained in this work suggests that the Enzquik Kit may in the future replace techniques used in the laboratory, since the incubation time of the kit is smaller than in other methodologies, generating an almost instantaneous result.
\end{abstract}

DOI: http://dx.doi.org/10.14295/ras.v32i2.29121

\section{INTRODUÇÃO}

A água é um bem natural, e a existência dos seres vivos depende diretamente desse bem, que é limitado, necessário à manutenção da vida, suporte dos ecossistemas e considerado direito fundamental universal (FLORES, 2011; LINO, 1998).

A quantidade de água disponível no planeta causa uma falsa impressão de ser um recurso inesgotável; mas, do volume total encontrado no planeta $97,5 \%$ é do tipo salgada, encontrada nos oceanos e mares, enquanto apenas 2,5\% correspondem à água doce, presente em rios, lagos, geleiras e subsolo. Desta quantidade, $68,9 \%$ encontra-se nas regiões polares em forma de geleiras, $29,9 \%$ no subsolo em aquíferos e somente $0,3 \%$ são águas dos rios e lagos disponível para consumo, porém a fração contaminada ainda é desconhecida (ALMEIDA, 2010). 
No Brasil, em função da degradação dos sistemas aquáticos, em 2005 o Conselho Nacional de Meio Ambiente publicou a Resolução 357 , que classifica os corpos hídricos de acordo com classes, segundo as principais finalidades desses corpos, e indica os parâmetros de qualidade dessas águas, para assegurar a proteção e uso sustentável dos mesmos (CONAMA, 2005; Souza et al., 2014).

O controle microbiológico da qualidade da água é inferido pela determinação da presença de microrganismos da microbiota intestinal; para ser utilizada a presença deles não deve exceder os limites de microrganismos patogênicos e bactérias indicadoras de contaminação, os coliformes totais e termotolerantes (CONAMA, 2005; FUNASA, 2013).

Esses microrganismos foram escolhidos como indicadores da qualidade da água por estarem presentes nas fezes de animais de sangue quente; apontando assim contaminação da água por fezes (BRANCO, 2010; LEBARON et al., 2005).

Os coliformes totais são bacilos gram-negativos podendo ser aeróbios ou anaeróbios facultativos, capazes de se desenvolverem na presença de sais biliares ou de agentes tensoativos que fermentam a lactose com produção de ácido, gás e aldeído à $35,0 \pm 0,5^{\circ} \mathrm{C} \mathrm{em}$ 24 - 48 horas, e podem apresentar atividade da enzima $\beta$ - galactosidase (MS, 2004; FUNASA, 2013).

O subgrupo dos coliformes que fermentam a lactose à $44,5 \pm 0,2^{\circ} \mathrm{C}$ em 24 horas, tendo como principal representante à Escherichia coli (E. coli) de origem exclusivamente fecal, é classificado como dos coliformes termotolerantes (FUNASA, 2013; MS, 2004; Tortora et al., 2005;).

A E. coli fermenta a lactose e manitol, com produção de ácido e gás à $44,5 \pm 0,2^{\circ} \mathrm{C}$ em 24 horas, produz indol a partir do triptofano, oxida-se negativamente, não hidrolisa a ureia e apresenta atividade das enzimas ß galactosidase e ß glucoronidase (FUNASA, 2013).

O Córrego Barreirinho, objeto desse estudo, tem sua nascente no Parque Estadual Serra do Rola Moça - Ibirité/MG, com outros seis mananciais que também têm suas nascentes no mesmo local. Todos esses mananciais estão localizados em área declarada pelo Governo Estadual como Área de Proteção Especial pois são responsá- veis por abastecer parte da região metropolitana de Belo Horizonte/MG (IEF, 2017).

O curso desse córrego é localizado em um bairro da periferia do município de Ibirité, sem saneamento, e a água é utilizada principalmente na irrigação de hortaliças, que são distribuídas para toda a região metropolitana de Belo Horizonte. Em outro ponto, o córrego recebe grande quantidade de dejetos urbanos (esgoto), o que coloca em risco a qualidade da água e a saúde da população que a utiliza (BATISTA, 2010).

Após pesquisas em plataformas acadêmicas como Google acadêmico, Scielo, CAPES, e no site da Prefeitura de Ibirité, nenhuma informação sobre a qualidade microbiológica desse córrego foi encontrada. $\mathrm{O}$ objetivo desse trabalho foi avaliar os parâmetros físico-químicos e microbiológicos, e classificar o Córrego Barreirinho de acordo com a Resolução N³57 (CONAMA, 2005).

\section{2. ÁREA DE ESTUDO}

O Município de Ibirité situado no estado de Minas Gerais tem área de $72,573 \mathrm{Km}^{2}$, onde predomina o cerrado, vegetação caracterizada pela existência de um estrato arbustivo com árvores espaçadas, retorcidas, em geral dotadas de cascas grossas e suberosas e de raízes profundas, e pela existência de um estrato herbáceo-graminoso (BATISTA, 2010).

Este município pertence à Bacia Hidrográfica do Rio Paraopeba e tem como principal curso de água o Ribeirão Ibirité (Figura 1). Os principais afluentes na margem esquerda são os córregos, do Barreirinho, Bálsamo, Rola-moça (Fubá), Taboões, Urubu, Sumidouro e Camargos (Terra do Feijão) e na margem direita, os córregos do Pelado, Palmares e Pintado (ANDRADE, 2017).

Na década de 1960, com a criação do município, surgiram a Refinaria Gabriel Passos - REGAP e a Represa Ibirité, formada pelo Ribeirão Ibirité e seus afluentes. Na década de 1980 os córregos do Bálsamo, Rola-moça (Fubá) e Taboões tiveram suas bacias protegidas por legislação estadual para garantir o abastecimento de água potável em parte da região metropolitana (IEF, 2017) para uma população estimada em 177.475 habitantes (IBGE, 2017). 
Figura 1 - (A) Localização geográfica do Córrego Barreirinho no município de Ibirité e os locais de amostragem. B- próximo à nascente, C- Irrigação de hortas, D- Dejetos urbanos
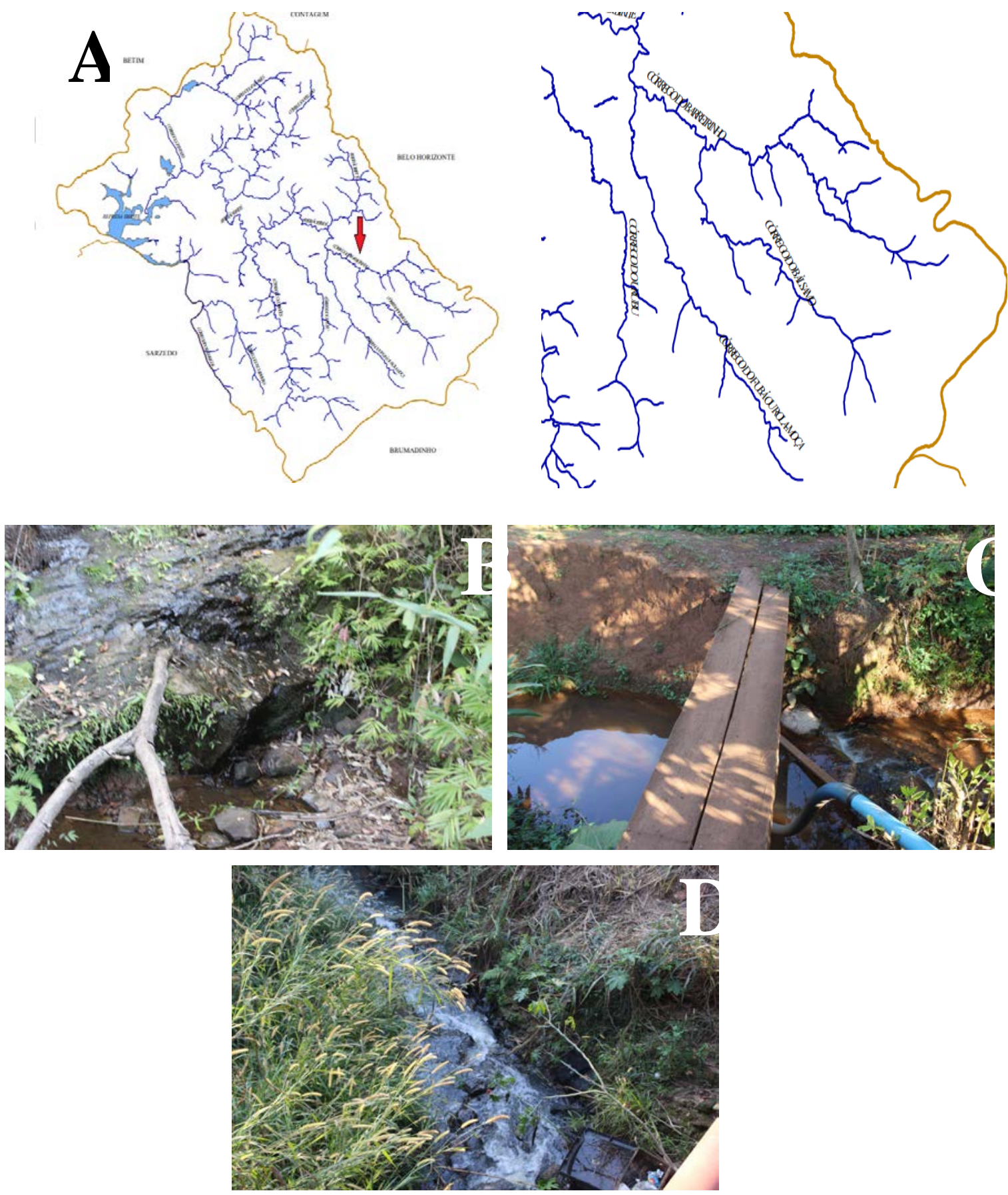

Fonte: Mapas disponibiizados pela prefeitura de Ibirité, fotos dos autores

\section{MATERIAIS E MÉTODOS}

As análises deste estudo foram realizadas em triplicata em amostras coletadas, bimensalmente nos meses de junho a novembro de 2015, em três pontos do Córrego Barreirinho: o primeiro próximo à nascente, o segundo na metade do curso d’água e o terceiro no final dele. Estes pontos foram definidos pelas coordenadas geográficas:

1. (PN) Próximo à Nascente: $20^{\circ} 2^{\prime} 18.25^{\prime \prime S}-44^{\circ} 1^{\prime} 27.97 " 0$;

2. (IH) Irrigação das hortas: $20^{\circ} 1^{\prime} 45.82^{\prime \prime S}-44^{\circ} 2^{\prime} 16.07 " 0$;

3. (DU) Dejetos urbanos: $20^{\circ} 1^{\prime} 44.15 " \mathrm{~S}-44^{\circ} 2^{\prime} 42.88^{\prime \prime} 0$.

\subsection{Coleta das amostras}

As coletas foram realizadas sempre à tarde. A coleta, acondicionamento, conservação das amostras e análises de quantificação de coliformes e heterótrofos totais foram realizados de acordo com os métodos especificados pela FUNASA (2013) e seguindo os procedimentos para ensaio microbiológico em águas superficiais estabelecidos pela Resolução 724 da ANA (2011).

\subsection{Análises Microbiológicas}

As análises foram realizadas através das técnicas de tubos múlti- 
plos para quantificação de coliformes totais e termotolerantes e a contagem total de bactérias heterotróficas pela técnica de Pour plate, conforme descrito pelo Manual Prático de Análise de Água da Fundação Nacional de Saúde (FUNASA, 2013).

Os procedimentos seguiram as etapas descritas sequencialmente, teste presuntivo, teste confirmativo, presença de coliformes termotolerantes e detecção de $E$. coli, e os resultados comparados com a Resolução N³57 CONAMA, 2005.

\subsubsection{Detecção de E.coli}

Os tubos com caldo lactosado com resultados positivos foram repicados em meio MacConkey pelo método de Pour Plate. Em seguida, foram incubados a $35^{\circ} \mathrm{C}$ por 24 horas. As colônias escuras rosadas, de 2 a $3 \mathrm{~mm}$, indicavam a presença de E. coli. (MARTINEZ; TADEI, 2005).

\subsection{Análises físico-químicas}

No local da coleta em triplicata foram medidos os parâmetros $\mathrm{pH}$ utilizando fitas medidoras, e temperatura utilizando termômetro $\left({ }^{\circ} \mathrm{C}\right)$. Todos os testes foram realizados em conformidade com a descrição no Manual Prático de Análise de Água da Fundação Nacional de Saúde (FUNASA, 2013) e os resultados foram comparados, com os valores indicados pela Resolução N³57 (CONAMA, 2005).

\subsection{Detecção Coliformes totais EnZquik}

Para a realização das análises com o Kit EnZquik, modelo 360/490 Dual Fluorometer disponibilizado pela empresa EnZitek Diagnostics, foram utilizados dois reagentes de composição não especificada pelo fabricante que funcionam como um sistema "chave e fechadura" das enzimas e substratos; as amostra foram lidas no aparelho que funciona por fluorimetria, os resultados foram expressos em um padrão numérico RFU (Unidade Fluorescente Relativa), para detectar a presença de coliformes termotolerantes. De acordo com o manual do kit para coliformes termotolerantes, valores acima de 500 RFU (Unidade Fluorescente Relativa), confirmam a presença desses micro-organismos.

O kit de detecção rápida foi concedido para testes a partir de agosto; por isso, mais experimentos são necessários para certificálo como método de análise rápida de água oriunda de amostras ambientais.

\subsection{Análises estatísticas comparativas}

Os experimentos foram avaliados estatisticamente pelo Programa Sigma Plot versão 11.0 onde foi aplicado o teste One Way ANOVA não paramétrico (HAMMER, et al. 2001).

\section{RESULTADOS E DISCUSSÃO}

Os pontos PN e IH do córrego Barreirinho são utilizados pelos moradores locais principalmente para irrigação de hortaliças; segundo a Resolução No 357 (CONAMA, 2005), águas destinadas à irrigação de hortaliças ou frutas que se desenvolvam rentes ao solo, que são ingeridas cruas, são classificadas como Tipo 1 ou seja, o valor de coliformes termotolerantes não deverá ultrapassar $200 \mathrm{NPM} / \mathrm{mL}$ (Número Mais Provável por mililitro) em $80 \%$ das amostras analisadas e o valor do $\mathrm{pH}$ deve estar entre 6,0 e 9,0. O ponto DU recebe grande quantidade de dejetos urbanos, não atendendo aos padrões estabelecido pela resolução.

Os resultados das medidas de temperatura e pH estão mostrados nas Figuras 2 e 3, respectivamente. No ponto PN a temperatura média foi $20^{\circ} \mathrm{C}$ e o $\mathrm{pH}$ médio 8 , no ponto $\mathrm{IH}$ a temperatura média foi $21^{\circ} \mathrm{C}$ e o $\mathrm{pH}$ médio 7 e no ponto $\mathrm{DU}$ a temperatura média foi $22^{\circ} \mathrm{C} \mathrm{e}$ o pH médio 7 .

Figura 2 - Temperatura média das amostras coletadas no Córrego Barreirinho -Temperatura das amostras analisadas nos meses de junho a outubro. As médias foram $20^{\circ} \mathrm{C}$ no ponto Próximo a Nascente, $21^{\circ} \mathrm{C}$ no ponto Irrigação de Hortas e $22^{\circ} \mathrm{C}$ no ponto Dejetos Urbanos

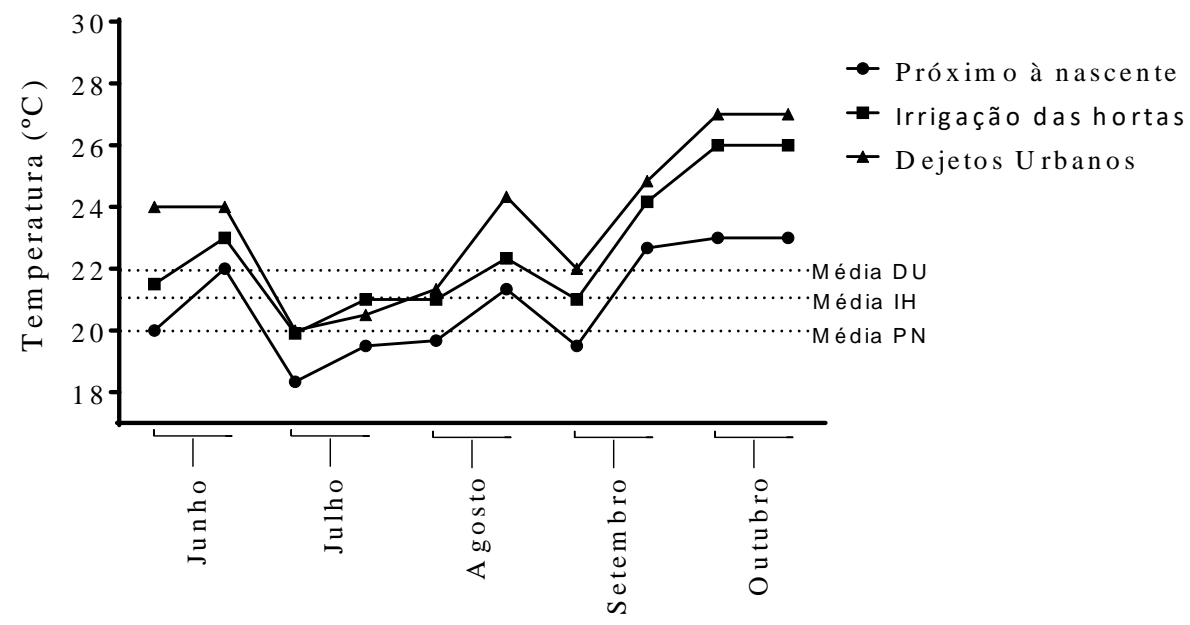

A temperatura não apresentou grandes variações pois os pontos não são distantes; de PN a IH 500m aproximadamente e de $\mathrm{IH}$ a DU300m aproximadamente. Pereira-Silva et al. (2011) estudaram as águas de três micros bacias hidrográficas em uma Unidade de Conservação do Estado de São Paulo, e também observaram que não houve variação de temperatura entre os pontos pela proximidade dos mesmos. 
Figura 3 - pH Médio das amostras coletadas no Córrego Barreirinho - 0 pH médio das amostras analisadas durante o período de junho a outubro foi: 8 no ponto Próximo a Nascente e 7 nos pontos Irrigação de Hortas e Dejetos Urbanos

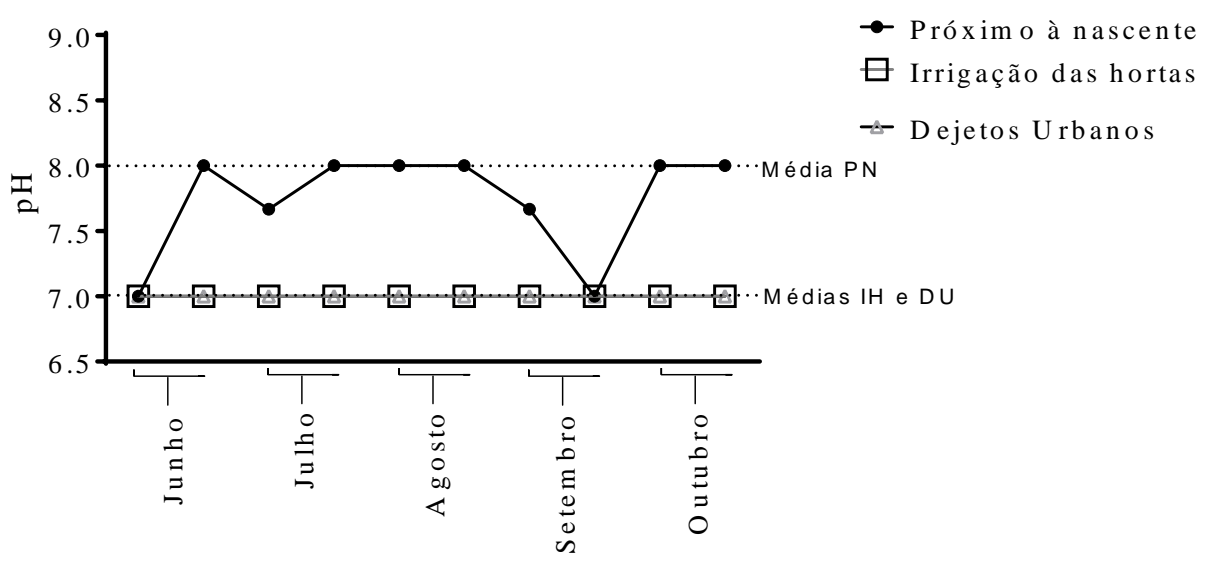

Todos os pontos analisados neste estudo tinham pH entre 6,0 e 9,0 indicando águas apropriadas para consumo de acordo com a Resolução N 357 (CONAMA, 2005 para este parâmetro. 0 trabalho de SOUZA, et al. (2014) na Bacia Hidrográfica do Rio Almada - BA, apresentou os mesmos resultados.

$\mathrm{O} \mathrm{pH}$ neutro e temperaturas mais elevadas já foram descritos como favoráveis ao crescimento bacteriano (TORTORA et al., 2005; FUNASA, 2013), o que também foi comprovado nestas análises microbiológicas.
Os resultados dos testes microbiológicos para detecção de coliformes totais mostraram no ponto PN $300 \mathrm{NPM} / \mathrm{mL}$; no IH 1600 $\mathrm{NPM} / \mathrm{mL}$ e no $\mathrm{DU}=1600 \mathrm{NPM} / \mathrm{mL}$; os dois últimos são valores máximos detectáveis pelo método utilizado (Figura 4).

Os resultados das análises para detecção de coliformes termotolerantes mostram no ponto PN $2 \mathrm{NPM} / \mathrm{m}$; no ponto IH $12 \mathrm{NPM} / \mathrm{mL}$ e no ponto DU $350 \mathrm{NPM} / \mathrm{mL}$ (Figura 5).

Figura 4 - Coliformes Totais encontrados no Córrego Barreirinho - Quantificação de coliformes totais em NPM/ $\mathrm{mL}$ dos pontos analisados durante o período de junho a outubro. 0 ponto PN apresentou valor próximo de 300 NPM e nos pontos IH e DU os valores máximos detectáveis pelo método de tubos múltiplos $1600 \mathrm{NPM} / \mathrm{mL}$

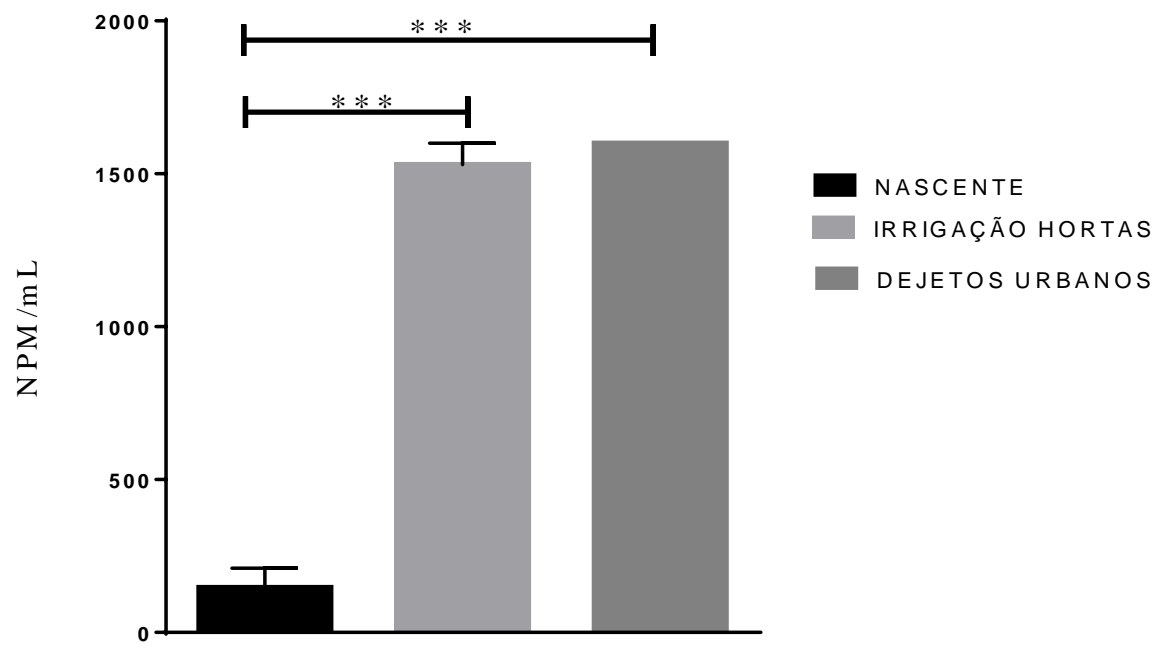

Os resultados indicam que as águas dos pontos $\mathrm{PN}$ e IH estão dentro dos padrões exigidos para consumo humano pela Resolução N³57 (CONAMA, 2005), mas o ponto DU não atende a esse padrão. No mês de setembro, os pontos IH e DU não atenderam as especi- ficações da resolução pela ocorrência de chuvas, que levaram ao curso d'água maiores quantidades de coliformes. Souza, et al. (2014), estudando o rio Almada encontraram resultado semeIhante. 
Figura 5 - Coliformes Termotolerantes no Córrego Barreirinho - Quantificação de Coliformes termotolerantes em NPM/ $\mathrm{mL}$ dos pontos analisados durante o período de Junho a Outubro. As médias foram $2 \mathrm{NPM} / \mathrm{mL}$, no ponto PN, $12 \mathrm{NPM} / \mathrm{mL}$ no ponto IH e $350 \mathrm{NPM} / \mathrm{mL}$, no ponto DU. Em setembro choveu um dia antes da coleta.

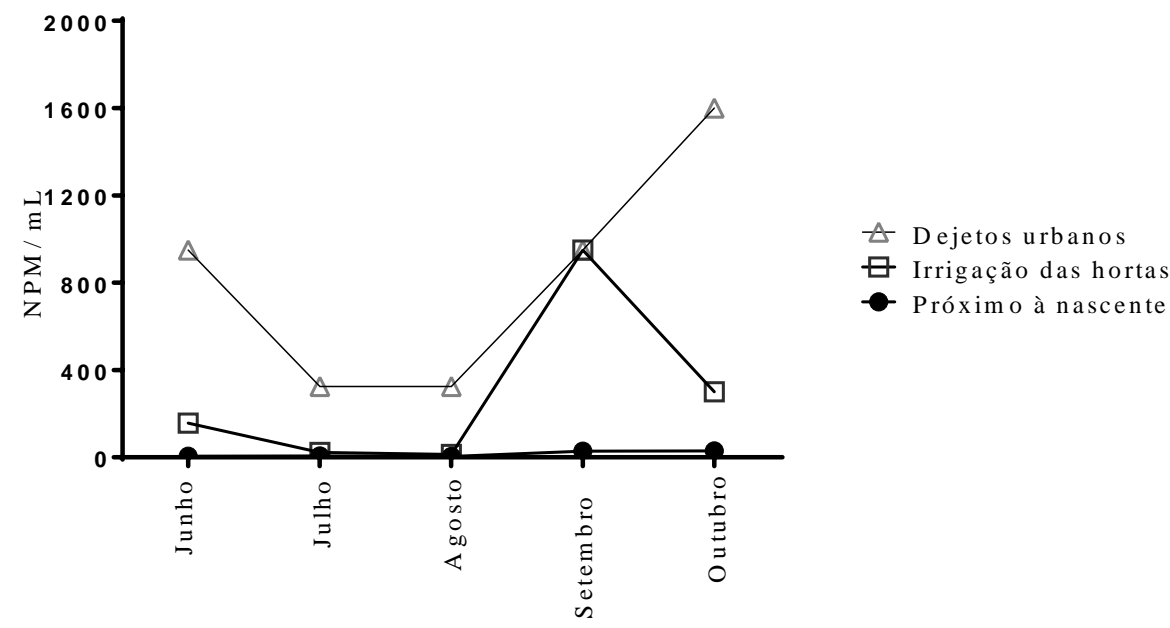

No teste de contagem total de bactérias heterotróficas, o ponto PN apresentou 218 colônias $/ \mathrm{mL}$; o ponto IH 2.248 colônias $/ \mathrm{mL}$ e o ponto DU 6.470 colônias/mL. Esse dado não é obrigatório pelos pa-

drões do CONAMA, mas auxilia a inferir sobre outros possíveis contaminantes do curso d'água além de coliformes termotolerantes ( $\mathrm{Fi}$ gura 6$)$.

Figura 6 - Bactérias Heterotróficas no Córrego Barreirinho - Quantificação de bactérias heterotróficas em Unidade Formadora de Colônia/mL, UFC/ $\mathrm{mL}$ dos pontos analisados durante o período de Junho a Outubro. As médias foram: UFC = 218 colônias $/ \mathrm{mL}$ no ponto $\mathrm{PN}, 2.248$ colônias $/ \mathrm{mL}$ no ponto IH e UFC= 6.470 colônias/ $\mathrm{mL}$ no ponto DU

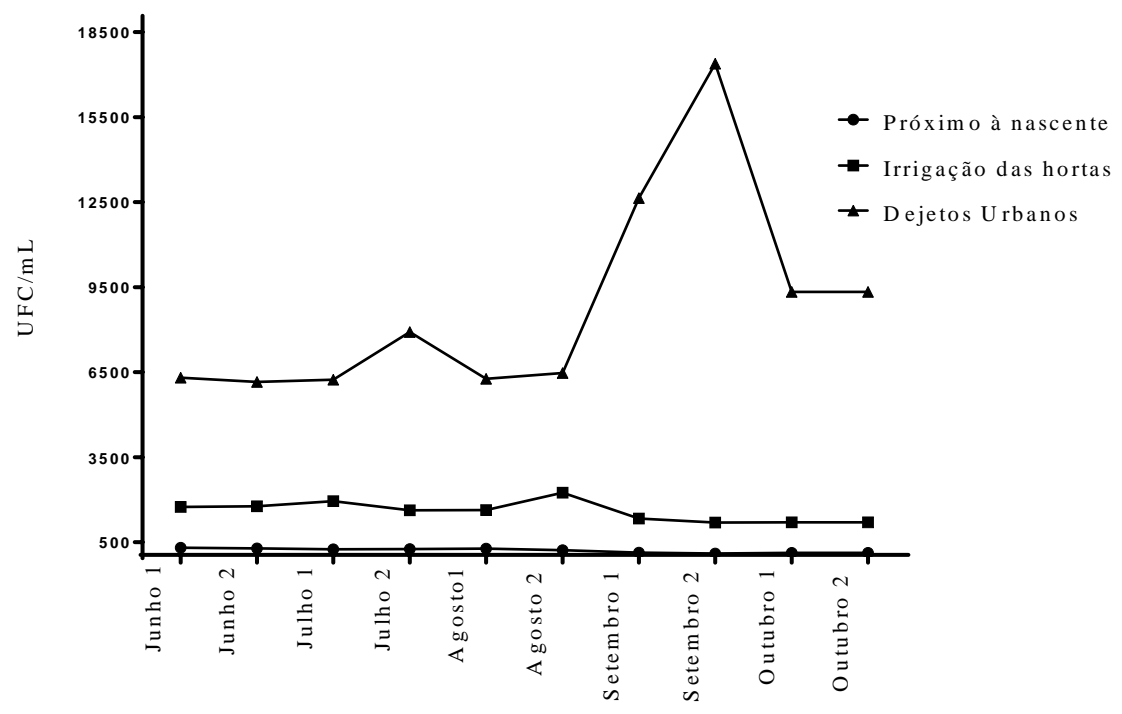

No teste de quantificação foram encontrados os maiores valores no ponto de DU, o que era esperado, uma vez que o Córrego Barreirinho recebe, ao longo de seu curso, descarga de dejetos urbanos. Os altos valores encontrados de bactérias heterotróficas, no mês de setembro são explicados pela ocorrência de chuvas que produziram lixiviações, carreando para o córrego grandes quantidades de matéria orgânica alterando a qualidade d'água principalmente nos pontos IH e DU.
Utilizando o ágar MacConkey (MARTINEZ; TADEI, 2005) para detecção de E.coli, os resultados mostraram colônias amarelas indicando ausência deste microrganismo no ponto PN e colônias rosas indicando presença de E.coli n os pontos IH e DU (Figura 7) o que está de acordo com as análises de coliformes termotolerantes. 
Figura 7 - Presença de bactérias termotolerantes e totais em placas com Ágar MacConkey. Na placa A, a presença de colônias amarelas e nas placas B e C predominam colônias rosas, confirmando a presença de bactérias termotolerantes
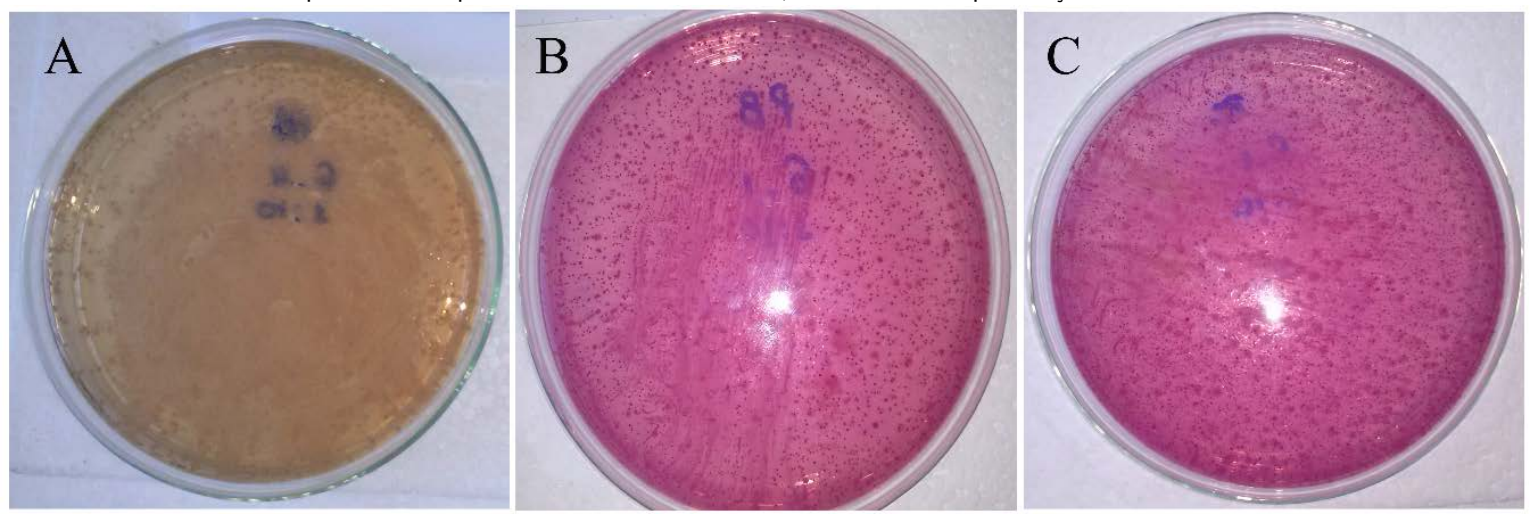

As análises realizadas com o Kit EnZquik apontaram resultados na ordem de 10 no ponto $\mathrm{PN}$ e 34 no ponto $\mathrm{IH}$, valores não significativos de coliformes termotolerantes. No ponto DU 6.649 RFU/mL. De acordo com o fabricante do Kit, valores acima de $500 \mathrm{RFU} / \mathrm{mL}$, in-

dicam água imprópria para consumo humano. Ou seja, os dados obtidos pela análise com o Kit (Figura 7) apontaram que água no ponto DU não devem ser consumidas.

Figura 7- Coliformes Totais no Córrego Barreirinho - Quantificação de Coliformes Totais dos pontos analisados durante o período de Agosto a Outubro. No ponto PN, $1 \mathrm{RFU} / \mathrm{mL}$ e no $\mathrm{IH} 34 \mathrm{RFU} / \mathrm{mL}$ caracterizando água apropriadas para consumo; no ponto DU 6.649 RFU/mL, indica água imprópria para consumo

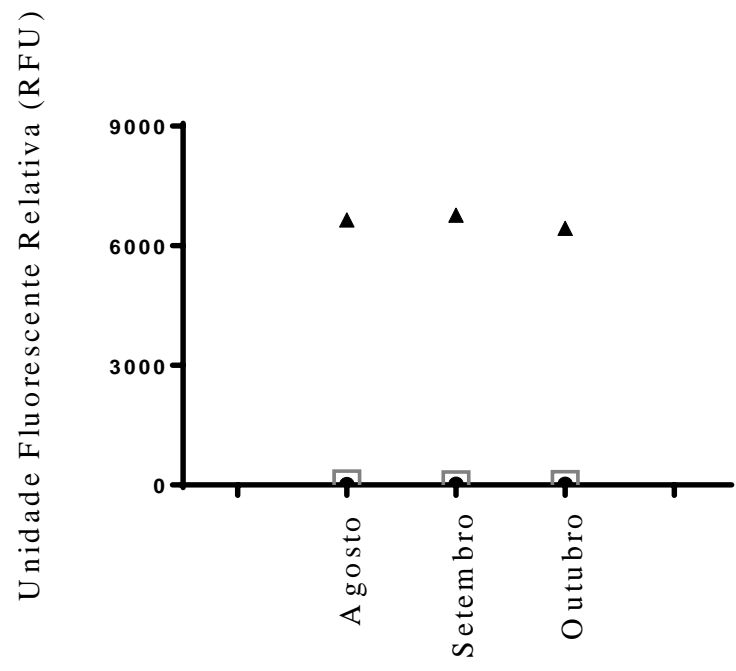

- Próximo à nascente

$\square$ Irrigação das hortas

- Dejetos Urbanos

\section{CONCLUSÕES}

Os resultados obtidos pelas análises de microorganismos patogênicos em amostras coletadas bimensalmente nos meses de junho a novembro de 2015 em três pontos do Córrego Barreirinho situado no município de Ibirité/MG monstraram que nos pontos próximos à nascente e no meio do curso d’água as águas são próprias para consumo, mas as águas no final do curso d’água localizado na periferia do município não são adequadas ao consumo de acordo com a Resolução no 357 do CONAMA.

O efeito do período chuvoso sobre a qualidade das águas no trecho na periferia é observado pelo aumento de coliformes termotolerantes do município produzido pelo carreamento de dejetos para o córrego. $\mathrm{O} \mathrm{pH}$ e a temperatura também medidos em todas as coletas mostraram valores na faixa do adequado para consumo das águas .

As análises realizadas pelo método convencional e com o Kit de Deteção Rápida EnZquik mostraram os mesmos resultados e que este kit após certificação de validação para amostras ambientais (dado não publicado), pode futuramente substituir as análises comumente realizadas na rotina dos laboratórios de controle de qualidade da água. Essa substituição permitiria obter um resultado rápido, pois o tempo de incubação é menor do que em outros testes utilizados. 


\section{AGRADECIMENTOS}

Agradecemos à EnZtek Diagnostics Incorporation por ter cedido gentilmente o Kit EnZquik para os testes neste estudo. Ao PAPq (Programa Institucional de Apoio à Pesquisa) da UEMG.

\section{REFERÊNCIAS}

ALMEIDA, M. Geografia global 2. 1. Ed,. São Paulo: Escala Educacional. p. 236.2010

ANA - Agência Nacional de Águas. Resolução $N^{\circ}$ 724. Disponível em: < http://arquivos.ana.gov.br/resolucoes/2011/724-2011.pdf>. Acesso em: 09. Mai 2018

ANDRADE, V.L. Apontamentos sobre unidades de conservação na cidade de Ibirité - MG: a legislação local e os impactos ambientais recentes nas paisagens rurais remanescentes de Helena Antipoff. Âmbito Jurídico, Rio Grande v. 20, n. 163, ago. 2017. Disponível em: < http://www.ambitojuridico.com.br/site/?n link=revista_artigos leitura\&artigo id=19418\&revista_caderno $=5>$. Acesso em maio 2018

BATISTA, V.P. Análise da Paisagem para identificação de pressão antrópica sobre Unidades de Conservação: estudo de caso da micro bacia do Córrego Barreirinho - Ibirité, 2010 - Minas Gerais. Monografia (Especialização). Universidade Federal de Minas Geraisp14. 2010.

BRANCO, S. M. Água: origem, uso e preservação. 2. ed. São Paulo: Moderna, 2010.

CONAMA.CONSELHO NACIONAL DO MEIO AMBIENTE. 2005. Resolução № 357. Disponível em: <http://www.mma.gov.br/port/conama/res/res05/res35705.pdf>. Acesso em: 22 mai. 2018.

FLORES, K. M. O reconhecimento da água como direito fundamental e suas implicações. Rio de Janeiro, Brasil. Revista da Faculdade de Direito da UERJ, v.19, n.1,2011.

FUNASA.FUNDAÇÃO NACIONAL DE SAÚDE. 2013. Manual prático de análise de água. Disponível em: <http://www.funasa.gov.br/site/wp-content/files_mf/manual_pratico_de_analise_de_agua_2.pdf. >. Acesso em: 22 maio 2018.
HAMMER, Ø., HARPER, D.A.T., and P. D. RYAN. PAST: Paleontological statistics: software package for education anda data analysis. Paleotologia Eletronica, v. 4, n.1, 9 p., 2001. Available from: http://palaeo-electronica.org/2001_1/past/issue1_01.htm. Access in: 16/01/2015.

IEF. INSTITUTO ESTADUAL DE FLORESTAS. Minas Gerais. 2017.Disponíve em:< http://www.ief.mg.gov.br/component/content/198?task=view> Acesso em 23 de maio, 2018.

IBGE. INSTITUTO BRASILEIRO DE GEOGRAFIA E ESTATÍSTICA. Minas Gerais: Ibirité. 2017. Disponível em: <https://cidades.ibge.gov.br/brasil/mg/ibirite/panorama>. Acesso em: 23mai. 2018

LEBARON, P., HENRY, A., LePEUPle, A. S., PENA, G., SERVAIS, P. An operational method for the real-time monitoring of $E$. coli numbers in bathing waters. Marine Pollution Bulletin. v. 50, p. 652-659, 2005.

LINO, M. A defesa dos interesses nacionais no domínio do abastecimento de água para consumo público e do saneamento de águas residuais urbanas. Lisboa, Portugal. Nação e defesa, v. 86 n. 2, p. 157-180, 1998.

MARTINEZ, M.B., TADEI., C.R. : Microbiologia..4. ed. São Paulo: Atheneu 2005, $718 p$

MS. - MINISTÉRIO DA SAÚDE. 2004. Portaria No 518. Disponível em: <http://www.aeap.org.br/doc/portaria518_de_25_d e_marco_2004.pdf>. Acesso em: 21 maio 2018

PEREIRA-SILVA, E. F.L, PIRES, J.S.R , HARDT, E. , SANTOS, J.E., FERREIRA, W.A. Avaliação da qualidade da água em microbacias hidrográficas de uma Unidade de Conservação do Nordeste do estado de São Paulo, Brasil. Revista Brasileira de Biociências, Porto Alegre, v. 9, n.3, p.371-381, jul./set.2011. Disponivel em http://www.ufrgs.br/seerbio/ojs/index.php/rbb/article/view/1758

SOUZA, J.R., MORAES, M.E.B., SONODA, S.L., SANTOS, H.C.R. A importância da qualidade da água e os seus múltiplos usos: caso Rio Almada, Sul da Bahia, Brasil. Fortaleza, Brasil. REDE - Revista Eletrônica do Prodema, v.8, n.1, p. 26-45, abr. 2014, Disponível em: < http://www.periodicos.ufc.br/rede/article/view/1115 >. Acesso em: 22 mai. 2018.

TORTORA, G. J., FUNKE, B. R., CASE, L. C. Microbiologia. 8. ed. Porto Alegre: Artmed, 2005. 894p. 